\title{
An Integrated Approach to Promoting Innovation in an Organization
}

\author{
Mohammad Essawi ${ }^{1} \&$ Oleg Tilchin ${ }^{1}$ \\ ${ }^{1}$ Al-Qasemi Academic College of Education, Baqa El-Gharbieh, Israel \\ Correspondence: Oleg Tilchin, Academic College of Education P.O. Box 124, Baqa El-Gharbieh 30100, Israel. \\ E-mail: otilchyn@yahoo.com
}

Received: March 24, 2014

Accepted: May 28, 2014

Online Published: June 22, 2014

doi:10.5539/ijbm.v9n7p70

URL: http://dx.doi.org/10.5539/ijbm.v9n7p70

\begin{abstract}
The suggested approach promotes innovation in organizations through construction and coordinated use of an accountability system, combined assessment system, and adaptive reward system. The approach provides the involvement of the largest possible number of employees in the creation and assessment of the innovation proposals. First, managers determine the possible directions for attaining the desired organizational result, form the reward conditions aimed at intensification of collaborative innovational activity of employees, and inform the employees about these conditions. Next, the submission of innovation proposals by employees is realized. Then, the submission process is managed. Next, the combined assessment of the employees' proposals is realized. The assessment involves managers and peer assessments of the proposals, and assessments of the willingness to collaborate in building innovations. It allows calculation of the proposal weight, which is determined as a sum of its coefficient of significance and a coefficient of collaboration. Next, the most preferable course of action, and the key employees who can attain the desired result are determined. Next, accountability at different levels for building innovations is set, owing to the presented innovation proposals. The extent of accountability of the employee conforms to the proposal weight. The greater extent of the accountability is set for the key employee. Finally, the adaptive rewarding of employees is accomplished. Innovation rewards are divided according to the proposals' weight. Adaptability of reward is reached by adjustment of reward size in accordance with the dynamics of creating the innovation proposals, the extent of accountability of the employees, and the roles of employees in the assessment of peer proposals.
\end{abstract}

Keywords: innovation, assessment, accountability, rewarding an organization

\section{Introduction}

Survival of an organization in a modern dynamic and competitive environment requires continuous improvement of organizational performance. It can be attained through creating an innovation culture directed towards developing the innovation capability of the organization (Lawson \& Samson, 2001; Horibe, 2009). The innovation capability of the organization provides for the possibility of innovation activity aimed at "development and implementation of new ideas by people who over time engage in transactions with others within an institutional order" (Van de Ven, 1986). An innovation is a result of realizing an innovation process (Poole, Van de Ven, Dooley, \& Holmes, 2000; Jones, 2012).

The innovation process can be presented by the following phases: determining strategic directions to improve organizational performance; creating innovation proposals according to specified directions; choice of the most effective proposals following assessments; and building innovations on the basis of these proposals.

Promotion of innovation can be attained through use of different mechanisms of innovation management (Bettina von Stamm, 2008; Shephard \& Ahmed, 2010; Ettlie, 2011; Tidd \& Bessant, 2013). One applicable mechanism is the knowledge management (KM) mechanism (Rodney, 2000). The central problem of KM consists in management of tacit knowledge, its conversion in explicit knowledge, and knowledge sharing among employees (Nonaka, 1994; Botha \& Snyman, 2008; Dawson \& Andriopoulos, 2014). Tacit knowledge is experience-based knowledge embodied in people (Sternberg \& Horvath, 1999). Explicit knowledge can be found in documents (Wellman, 2009). The most valuable knowledge is tacit knowledge (Hislop, 2009; Dalker, 2011). This type of knowledge promotes innovation and sustains competitive advantage (Gamble \& Blackwell, 2001; Wellman, 2009). However, management of tacit knowledge is extremely problematic. 
The culture of organizations can have a negative influence on innovation because of the presence of an obstacle in knowledge sharing among employees through the organization. The obstacle is caused by rigid organizational structure, and restriction of employees that prevents them from experimenting with new ways of thinking and acting. However, organizations should possess a culture providing motivation for innovation with the help of an appropriate reward system (Nacinovic, Galetic \& Cavlek, 2009; Glasberg \& Ouerghemi, 2011).

A significant element of promoting innovation is accountability, which gives employees and an organization a sense of purpose (Evans, 2008). Creating efficient personal accountability should be based on willingness and the desire of an employee to realize actions.

Hence, effective KM in an organization can be attained by creating an innovation culture, which determines the new way of thinking and behavior in employees, leading to the building of high-quality innovation (Horibe, 2009). The innovation culture requires creating a specific result-based accountability system, effective assessment system, and adaptive reward system for building innovation. It should provide the involvement of a maximal quantity of employees in an innovation process, and collaboration among employees through all levels of the organizational structure.

Therefore, the goal of this paper is to develop an integrated approach for promoting innovation in an organization through coordination of work and a result-based accountability system, combined assessment system, and adaptive reward system.

\section{Literature Review}

Research directed towards promoting innovation in an organization is examined. It involves: improvement of organizational performance through innovation; the influence of organizational culture on innovation, knowledge management, creating accountability, and motivating employees through rewards.

Improvement of organizational performance through innovation requires realizing determined practical actions. Tidd \& Bessant (2013) determines the requirements for building an innovative organization. These requirements are shared vision, leadership providing a creative climate, appropriate organizational structure, key employees, high involvement in innovation, effective teamwork, pushing for knowledge, and observing others. Brands \& Kleinman (2010) suggest the practical steps to achieve improvement of organizational performance and business growth through innovation. The basic steps are inspiring, creating needed values, building accountability, idea management, observing, measuring, and rewarding. Ettlie (2011) unfolds the dependence on innovation strategies from organizational strategies. The author describes the innovation process and shows the important role of collaboration in this process.

Innovation in an organization can be influenced by a specific organizational culture. Essawi (2012) created the structured dynamic value confrontation leadership model for organizational culture change. The model provides constructive confrontation by changing current employee values according to the required organizational values. Martins \& Martins (2002) suggest determinants of organizational culture that influence creativity and innovation. The determinants are leadership strategy, flexible organizational structure allowing freedom and group interaction, recognition and reward, behavior that encourages innovation, and communication possibility. Westover (2011) describes leadership practices and methods for creating organizational culture to promote innovations for driving organizational effectiveness. Wellman (2009) describes leadership roles that can facilitate organizational culture change in providing effective $\mathrm{KM}$.

Organizational culture fostering innovation should induce knowledge sharing among employees. Thus, Bukowitz \& Williams (1999), Park \& Schulte (2004), and Gamble \& Blackwell (2001) emphasize the importance of an organizational culture promoting the willingness of its employees to share their knowledge that allows for the transfer and the creation of knowledge. O'Dell \& Hubert (2011) illustrate the building of a knowledge sharing culture as an important part of their strategy for making KM successful. The authors claim that recognition is needed to energize employees.

Pasher \& Ronen (2011) affirm that successful knowledge creation and knowledge sharing in an organization are a result of a management style based on shared cultural values. The values are trust, innovation, and respect for employee knowledge. The authors emphasize the necessity to encourage employees to contribute their knowledge in the means of organizational development and suggest methods for promoting interactions in order to foster knowledge creation and knowledge sharing in organizations.

Success of innovation activity in an organization depends on efficiency of KM. Hislop (2009) represents an approach to the facilitation of KM through organizational culture change and human resource management practices, including performance evaluation and rewarding employees. Rodney (2000) examines the constitutive 
role of KM in supporting, sustaining and enhancing innovation activity in organizations. The author suggests a KM model oriented to increase innovation within the organization. Seidler-de Alwis, Hartmann \& Gemünden (2004) substantiate the crucial role of tacit knowledge on the innovation management process. It allows the authors to represent innovation management as tacit knowledge management, and to develop an integrated model describing the impact of tacit knowledge on successful innovation management.

KM characterizes innovation capability of an organization. Cavusgil, Calantone \& Zhao (2003) examine different aspects of the relationship between tacit knowledge transfer and innovation capability of an organization. Lawson \& Samson (2001) define innovation management as a form of organizational capability. The authors suggest an aggregate of elements characterizing an innovation capability of an organization. The aggregate embraces vision and strategy, competence and organizational intelligence, creativity and idea management, organizational structures and systems, culture and climate, and technology management.

Creating correct result-based accountability promotes innovation in an organization. Samuel \& Chiche (2004) determine accountability as action that's consistent with the desired outcomes of an employee. The authors have developed the personal accountability model, furthering realization of intention to stay accountable. The model components are: recognize, own, forgive, self-examine, learn, take action. Connors \& Smith (2011) consider creation of accountability culture in an organization as a result of consecutive realization of the steps conducive to employee accountability. These steps are: see it, own it, solve it, and do it. Evans (2008) claims success of an organization requires embedding accountability into its strategy, determining clear expectations, and creating relationships among team members based on accountability. Owing to this, job satisfaction and organizational performance are improved.

Motivation of employees through reward can serve as a basic factor of innovation intensification. Nacinovic, Galetic \& Cavlek (2009) argue that an organization must have an appropriate reward system that promotes innovation. Glasberg \& Ouerghemi (2011) emphasize the importance and the key role of employee motivation for building innovation in an organization. They assert a reward system within an organization motivates creativity, engendering innovation from employees.

The analysis of the above publications shows that the challenges associated with the promotion of innovation in an organization through the providing of effective KM and energizing the creativity of employees remain. An organizational environment inducing employees toward innovation has not been created. Self-forming collaborative groups of employees through all levels of organizational structure aimed at building innovation have not been specified. A balance between competition and collaboration among employees for innovation has not been achieved. Stimulation and facilitation of employees' tacit knowledge externalization have not been realized. Recognizing and rewarding employees has not been connected with the measurement and the assessment of their accountability and contribution to innovation process. The key employees who can be accountable for attaining the desired results and the most preferable course for organization performance improvement are not determined.

Therefore, there is a need for development of the integrated approach aimed at promoting innovation of employees in an organization through building and providing coordinated use of a result-based accountability system, a combine assessment system, and an adaptive reward system.

\section{The Integrated Approach to Promoting Innovation in an Organization}

The review of research allows for conclusion that desired organizational results can be attained by creating an organizational environment that induces innovation of employees.

The goal of the approach is to promote the creation of innovation proposals by employees, determine the most preferable course of action, and determine the relevance of key employees in building innovations conducive to improvement of organizational performance.

The goal is reached by providing:

- Awareness in employees about the possible directions conducive to a desired organizational result, reward conditions, and innovation activity in their peers;

- Managed submission of the innovation proposals, engendering self-forming collaborative groups for building innovation through all levels of organizational structure, and a balance between competition and collaboration among employees;

- Combined assessment of the innovation proposals, allowing determination of the most preferable course of action and the key employees;

- Building employee accountability for innovation based on intellectual willingness; 
- Adaptive rewarding.

The approach intends consistent performance of the determined steps.

\section{Step 1: Determination and declaration of the reward conditions and the possible directions conducive to a desired organizational result}

An organizational result which should be attained by an organization is established. Attaining the result requires productive innovation activity from employees. The possible directions to attain the desired organizational result are determined and declared by managers. The employees are informed about the need to submit their innovation proposals according to the possible directions.

Aspiration to induce the employees toward innovation activity causes development of the formative conditions of rewards for innovation proposals conducive to attaining the desired organizational result. All employees participating in the creation and assessment of peers' innovation proposals are awarded according to determined conditions. The reward conditions take into account all of the possible roles of an employee in the innovation process. The roles are: creator of an innovation proposal; valuator of the peer proposal; and wishing to collaborate in building the innovation on the basis of the proposal. Prior employee familiarity with the reward conditions is realized.

\section{Step 2: Managed submission of innovation proposals by employees}

An employee explores the possible directions that could lead to attaining the desired result. Then, self-evaluation of an employee's ability to prepare innovation proposals according to the directions is realized. Owing to self-evaluation, the employee submits his (her) proposals.

The employee proposals are manifested in the organization for peers' awareness.

The employee examines the peers' innovation proposals. As a result of examination of peer proposals and self-evaluation of his (her) ability, the employee makes a decision to submit a personal proposal, or to assess peer proposals, or to collaborate in building innovations on the basis of peer proposals. Thereby, a balance between competition and collaboration among employees is attained. If an employee can't create a proposal, he (she) can't compete with peers, but can make a decision to collaborate. If an employee created a proposal, he (she) competes with his (her) peers. Yet, he (she) can also collaborate with other employees for building innovations based on the proposals.

The aspiration to encourage creation of qualitative proposals requires management of innovation proposal submission. The management introduces the limitations and the changes. The limitations are the general quantity of proposals that may be submitted by an employee; the quantity of the proposals that may be submitted by an employee for each possible direction; the quantity of the proposals and the development and realization of which an employee may collaborate on; the quantity of the proposals which may be assessed by every employee. Restricting the general quantity of the proposals that may be submitted induces an employee to prepare qualitative proposals that correspond the most to his knowledge. Restriction of the quantity of the proposals that may be assessed by every employee is created by two factors: employee inducement to choose for assessment only the proposals that correspond the most to their knowledge; aspiration of employees to receive the maximal reward for assessment.

Changing the quantity of the proposals which may be submitted by an employee relative to each possible direction allows for receiving more proposals corresponding to the directions that are the most suitable for attaining the desired result with respect to the standpoint of the participating managers. A change in the quantity of the proposals where the employee is allowed to collaborate with their authors is created by the aspiration to balance between energizing collaboration and motivating employees to choose the proposals best for collaboration and building corresponding innovations that would be the most suitable in terms of knowledge and preferences.

\section{Step 3: Combined assessment of the innovation proposals}

Managers and peers assess the innovation proposals. Availability of manager assessment in the combined assessment of the employee proposals characterizes the extent of manager influence on choosing the most productive proposals. The absence of manager assessment is the evidence of absolute independence of employees in assessing proposals of their peers.

Assessment of an innovation proposal is realized on the basis of the established range from 0 to 5: 0 - a proposal is not actual; 5 - a proposal is a breakthrough. 


\section{Example 1:}

Assessments of $\mathrm{j}$ proposal by four employees are $2,4,5,5$. Then, the total assessment $\mathrm{c}_{\mathrm{j}}$ of the proposal is equal to 16 .

The significance coefficient $\mathrm{s}_{\mathrm{j}}$ of $\mathrm{j}$ proposal is calculated by the formula:

$$
s_{j}=c_{j} / 5 n_{j},
$$

where:

$c_{j}$ is total assessment of $\mathrm{j}$ - proposal, $\mathrm{j}=1, \ldots, \mathrm{m}$; $\mathrm{m}$ is the quantity of the assessed proposals,

$n_{j}$ is the quantity of the assessment participators of $j$ - proposal.

The range of the significance coefficient is 0 to 1 .

\section{Example 2:}

The total assessment $c_{j}$ of $j$ - proposal by four employees is equal to 16 . Then, the significance coefficient $s_{j}$ of the proposal calculated by formula (1) is equal to 0.8 .

The assessment participators in an innovation proposal can express the wish to collaborate with the author of the proposal in building the innovation, since according to their opinions the proposal corresponds to their professional abilities, and with the proposal author, they can work effectively. The collaboration coefficient for each proposal can be calculated. The collaboration coefficient for the proposal with maximal quantity of the desire to collaborate is set as a fixed value. The collaboration coefficient for each from others' proposals is determined relative to the fixed value pro rata number of wishing to collaborate.

\section{Example 3:}

There are five innovation proposals. The number of employees wishing to collaborate in building innovation on the basis of each proposal equals $5,4,3,2,1$, accordingly. The maximal quantity of wishing to collaborate equals 5. This value corresponds to the first proposal. The collaboration coefficient for this proposal is set equal 0.15 . Then, the collaboration coefficients for others' proposals equal $0.12,0.09,0.06$, and 0.03 , accordingly.

An innovation proposal weight can be determined as the sum of its significance coefficient and the collaboration coefficient. The proposals are ranged on the basis of calculated weights. Thereby, the assessment system involves total assessments of the proposals, the significance coefficients of the proposals, the collaboration coefficients for the proposals, and the proposal weight, and provides the relationship among these components.

\section{Step 4: Determination of the most preferable course of action and key employees for attaining the desired results}

At first, suitable directions for attaining the result are determined. These directions are revealed on the basis of innovation proposals presented by employees according to the possible directions to attain the desired organizational result and are set by management. Thus, the lack or minimal quantity of the received innovation proposals relative to some possible direction reveals its infeasibility for attaining the result because of the shortage of intellectual possibilities of employees corresponding to this direction. On the other hand, the maximal quantity of the received innovation proposals relative to some possible direction allows characterization of the direction as suitable for attaining the result due to the availability of the necessary intellectual abilities of employees.

Then, the most preferable course of action to attain the necessary organizational result is chosen by managers from the suitable directions due to comparison of total assessment weights of the proposals presented relative to each from these directions. The direction having maximal total assessment weight from presented proposals receives status of the preferable course of action.

Finally, the key employees for attaining the desired results are determined. They are the authors of the proposals presented relative to the most preferable course of action.

\section{Example 4:}

There are two suitable directions for attaining the necessary organizational result; the assessment weights of innovation proposals presented relative to the first direction equal 8.15,9.12, 7.09, 8.06, and 5.03, and the assessment weights of innovation proposals presented relative to the second direction equal $7.15,1.12,8.09$, and 6.06. Then, total assessment weights of the proposals presented relative to these directions are 37.45 and 22.42 , accordingly. Comparison of the total assessment weights of the corresponding proposals allows for the 
conclusion that the first suitable direction must be chosen as the most preferable course of action for attaining the necessary organizational result.

\section{Step 5: Creating accountability for innovation}

Submission of the innovation proposals by the employee is evidence of his (her) intellectual willingness in taking high level accountability for building the corresponding innovations.

The desire for collaboration in building innovation propels the employee to share accountability with the author of the proposal. It allows for determination of the peers suitable for the collaborative building of innovation together with the proposal's author, and to create a middle level of accountability. The desire to assess the peer proposals creates low-level accountability of the employee.

The extent of employee accountability conforms to weight of his innovation proposal: the bigger its weight, the more accountability from the employee for innovation. Key employees should take accept greater accountability, since they are accountable for building innovations on the basis of their proposals. Furthermore, if there are some proposals from the key employee relative to preferable course actions, then his summary extent accountability equals the sum of the extent of accountability corresponding to the proposals.

\section{Step 6: Adaptive rewarding of employees for innovation}

Innovation reward is divided according to the innovation proposal's weight: the bigger its weight the greater the reward that's received.

\section{Example 5:}

The size of the innovation reward equals $\$ 1,000$. There are five innovation proposals. The proposal weights equal $0.7,0.6,0.5,0.4,0.3$, accordingly. Then, distribution of reward among the proposals results in $\$ 280, \$ 240$, $\$ 200, \$ 160, \$ 120$, accordingly. The accountability extent of the proposal's first author is bigger.

The predetermined size of the proposal reward is divided between the author of the proposal and the participators in its assessment, e.g. the author receives $80 \%$ and the participants receive $20 \%$ of the proposal reward.

\section{Example 6:}

The predetermined size of the first proposal reward is $\$ 280$ (Example 5). Then, rewarding the author of the proposal equals $\$ 224$. Rewarding the peers assessing the proposal equals $\$ 56$.

Rewarding peer-participators of proposal assessment is divided on the basis of their roles, i.e. whether an employee only assesses an innovation proposal or wishes to collaborate with the author during building an innovation based on a proposal. The employee wishing to collaborate should have a higher award.

Integral personal award of an employee is calculated by the summation of his awards as the author of a proposal, participator of assessment of peer proposals, and in wishing to collaborate in the realization of the proposals.

As appears from the above, the place of the proposal is determined based on its weight, which reflects the assessments of managers and peers, and the wish to collaborate. However, the proposals with equal weights may get different rewards, which are caused by the aspiration to provide preferable influence of one of its parameters forming the assessment weight. Dividing the reward determined for the proposal between its author and the employees assessing it depends on the need to stimulate either the preparation or assessment of the proposals. The reward intended for the employees assessing proposals is divided among them by taking into account their roles in the assessment. If there is necessity to stimulate collaboration in an organization, then the greater part of the reward is presented to those wishing to collaborate. Furthermore, the proposal presented relative to the most preferable course of action for attaining the necessary organizational result must receive a greater reward.

The adaptability of rewarding is attained owing to adjustment of the size of reward with regard to the dynamics of the process of creating innovation proposals, the extent of an employee's accountability (an employee which holds greater accountability receives a greater reward), and the roles of employees in assessment of peer proposals.

Thereby, an adaptive reward system provides coordinated functioning in its components. The components divide innovation rewards among the proposals according to their weights; divide the proposal reward between the author of the proposal and the participants in its assessment; divide the reward of peer-participators of a proposal assessment according to their roles in assessment; calculate the integral personal award; adjust the reward size according to the dynamics of creating innovation proposals, and determine the extent of employees' accountability. 


\section{Conclusion}

The suggested integrated approach promotes creation of innovation proposals by employees, determines the most preferable course of action, and the relevance of the key employees who can take accountability for building innovations conducive to attaining the desired result in an organization reached by providing awareness in employees about the possible directions of innovation activity, the reward conditions, and innovation proposals from their peers; coordinated functioning of the combined assessment system, the result-based accountability system, and the adaptive reward system.

The assessment system realizes managers and peer assessment, and the assessment of willingness and desire to collaborate. Owing to that, the proposal weight is set. The proposal weight is calculated as the sum of the significance coefficient and the collaboration coefficient. The proposals are ranged on the basis of calculated weights.

The accountability system sets the different levels of accountability for employees and their extent of accountability, and allows for sharing of accountability among employees. The extent of accountability of the employee conforms to the proposal weight, and the status of the proposal in attaining the desired organizational result. Sharing accountability is provided owing to self- formed collaborative groups for building innovations through all levels of organizational structure, and presence of the balance between competition and collaboration of employees.

The adaptive reward system induces employees' innovation activity through adjustment of the size of rewards according to the dynamics of the process of creating innovation proposals, roles of employees in the assessment of peer proposals, and the accountability extent of the employees.

\section{References}

Bettina, S. (2008). Managing Innovation, Design and Creativity (2nd ed.).

Botha, A., Kourie, D., \& Snyman, R. (2008). Coping with Continuous Change in the Business Environment, Knowledge Management and Knowledge Management Technology. Chandice Publishing Ltd.

Brands, R. F., \& Kleinman, M. J. (2010). Robert's Rules of Innovation: A 10-Step Program for Corporate Survival (1st ed.).

Bukowitz, W., \& Williams, R. (1999). The Knowledge Management Fieldbook. Financial Times/Prentice Hall.

Cavusgil, T. S., Calantone, R. J., \& Zhao, Y. S. (2003). Tacit Knowledge Transfer and Firm Innovation Capability. The Journal of Business and Industrial Marketing, 18(1), 6-20. http://dx.doi.org/10.1108/08858620310458615

Connors, R., \& Smith, T. (2011). Change the Culture Change the Game. Penguin Group Inc.

Dalker, K. (2011). Knowledge Management in Theory and Practice. The MIT Press.

Dawson, P., \& Andriopoulos, C. (2014). Managing Change, Creativity and Innovation. SAGE Publications Ltd.

Essawi, M. (2012). The Value Confrontation Leadership Model. International Leadership Journal, 4(2), 72-82

Ettlie, J. (2011). Managing Innovation (2nd ed.). Taylor \& Francis.

Evans, H. J. (2008). Winning with Accountability: The Secret Language of High-Performing Organizations. Corner Stone Leadership Institute

Gamble, P. R., \& Blackwell, J. (2001). Knowledge Management: A State of the Art Guide. Kogan Page Ltd.

Glasberg, R., \& Ouerghemi, K. (2011). Innovation in Human Resources. A Theoretical Advancement on Employee Motivation and Organizational Innovation. 2nd International Conference on Economics, Business and Management. Singapore: Ipedr Iacsit Press.

Hislop, D. (2009). Organizational Culture and Knowledge Management (3rd ed.). USA: Oxford University Press.

Horibe, F. (2009). Creating the Innovation Culture: Leveraging Visionaries, Dissenters and Other Useful Troublemakers (1st ed.).

Jones, T. (2012). On Innovation. Essential Ideas, Inc.

Lawson, B., \& Samson, D. (2001). Developing Innovation Capability in Organizations: A Dynamic Capabilities Approach, International Journal of Innovation Management, 5(3), 377-400. 
Martins, E., \& Martins, N. (2002). An Organizational Culture Model to Promote Creativity and Innovation, Journal of Industrial Psychology, 28(4), 58-65.

Nacinovic, N., Galetic, L., \& Cavlek, N. (2009). Corporate culture and innovation: implications for reward systems. World Academy of Science, Engineering and Technology, 397-402.

Nonaka, I. (1994). A Dynamic Theory of Organizational Knowledge Creation. Organizational Science, 5(1), $14-37$. Retrived from http://www1.uni-hamburg.de/ami/lehre/Veranstaltungen/WS_0607/Innomarketing/Rueckschau/Nonaka_OS 1994.pdf

O'Dell, C., \& Hubert, C. (2011). The New Edge in Knowledge: How Knowledge Management Is Changing the Way We Do Business (1st ed.).

Park, H., Ribiere, V., \& Schulte, W. (2004). Critical Attributes of Organizational Culture that Promote Knowledge Management Technology Implementation Success. Journal of Knowledge Management, 8(3), 106-117. http://dx.doi.org/10.1108/13673270410541079

Pasher, E., \& Ronen, T. (2011). The Complete Guide to Knowledge Management: A Strategic Plan to Leverage Your Company's Intellectual Capital (1st ed.).

Poole, M. S., Van de Ven, A. H., Dooley, K., \& Holmes, M. E. (2000). Organizational Change and Innovation Processes: Theory and Methods for Research, USA: Oxford University Press.

Rodney, Mc. A. (2000). Knowledge Management as a Catalyst for Innovation within Organizations, A Qualitative Study. Knowledge and Process Management, 7(4), 233-241. http://doi.dx.org/10.1002/1099-1441(200010/12)7:4<233::AID-KPM94>3.0.CO;2-F

Samuel, M., \& Chiche, S. (2004). The Power of Personal Accountability: Achieve What Matters to You (1st ed.). Xephor Press.

Seidler-de, A., Ragna, H., Evi, G., \& Hans, G. (2004). The role of Tacit Knowledge in Innovation Management. 20th Annual IMP Conference in Copenhagen.

Shephard, P., \& Ahmed, C. (2010). Innovation Management. Pearson

Sternberg, R. J., \& Horvath, J. A. (1999). Tacit Knowledge in Professional Practice: Researcher and Practitioner Perspectivest (1st ed.). Psychology Press

Tidd, J., \& Bessant, J. (2013). Managing Innovation: Integrating Technological, Market and Organizational Change (5th ed.).

Van, D. V., \& Andrew, H. (1986). Central Problems in the Management of Innovation. Management Science, 32(5), 590-607. Retrieved from http://www.jstor.org/stable/2631848

Wellman, J. L. (2009). Organizational Learning. Palgrave Macmillian.

Westover, J. H. (2011). Organizational Culture, Learning, and Knowledge Management. Common Ground Publishing.

\section{Copyrights}

Copyright for this article is retained by the author(s), with first publication rights granted to the journal.

This is an open-access article distributed under the terms and conditions of the Creative Commons Attribution license (http://creativecommons.org/licenses/by/3.0/). 